\author{
Andrej Ule
}

\title{
Pomen konfucijanske misli za ohranjanje človečnosti in razumnosti $v$ sodobnem svetu
}

Ključne besede: humanost, racionalnost, razumnost, konfucijanstvo, sklepanje po analogiji, samouresničenje

DOI: $10.4312 /$ ars.10.1.119-132

\section{Uvod: sovpadanje družbenih in moralnih kriz sodobnega človeštva}

Mešanica ekonomskih, političnih, moralnih, ekoloških in drugih kriz sodobnega globaliziranega sveta se ne kaže le kot kriza sodobnih družb, temveč in celo predvsem kot kriza vsakega posameznika. Ta kriza spodjeda naše zaupanje $\mathrm{v}$ temeljna pravila obnašanja, $\mathrm{v}$ naše osnovne ideale, celo $\mathrm{v}$ načela racionalnega mišljenja. Sodobne ekonomske krize v lokalnih in globalnih razmerjih ter kriza globalne tehnokracije so razrahljale naše zaupanje $\mathrm{v}$ človeško racionalnost, kriza zaposlovanja je razrahljala naše zaupanje v predstavo o tem, da nam stalna zaposlitev zagotavlja stabilen obstoj kot ljudi, politične krize so pretresle naše zaupanje $\mathrm{v}$ demokracijo, splošna odvisnost ljudi od medijev in vsesplošno vdiranje $v$ njihovo zasebnost sta pretresla naše zaupanje $\mathrm{v}$ avtonomijo posameznika. Ob tem povečevanje števila nesmiselnih izbir, s katerimi smo soočeni, spodjeda naše zaupanje v človekovo svobodo. Zaupanje v racionalnost, demokracija, avtonomnost, svoboda in zaposlitev predstavljajo osnovne "sestavine» človečnosti in humanizma, kot ju pojmujemo v t. i. zahodnem svetu. Soočeni smo z zunanjim in notranjim kolapsom teh temeljnih pojmov in simbolnega sistema, ki jim ustreza.

Ni torej čudno, če povprečni "zahodnjak«, ki se zaveda teh razmer, doživlja precejšen duševni in telesni nemir. Zdi se, da nam manjka duha ter predvsem vere $\mathrm{v}$ človečnost in $\mathrm{v}$ njeno sposobnost naslonitve na duha, ko se soočamo $\mathrm{z}$ osebnimi in družbenimi krizami. Ni čudno, da je zahodni svet poln nemirnih "popotnikov«, ki se obračajo na Vzhod v svojem iskanju tega, kar nam (domnevno ali stvarno) manjka na Zahodu. Številnim od teh popotnikov se zdi prav kitajska kultura ključni izvor možnih rešitev iz sodobne krize zahodnega in pozahodenega sveta. Vsaj tradicionalna kitajska kultura se zdi polna zamisli o globokih in celostnih povezavah med duhom 
in človečnostjo. Pojavlja se vprašanje, ali nam lahko te zamisli ponudijo nove pojme človečnosti in racionalnosti, takšne, ki presegajo domet evropskega humanizma, dogmatskega racionalizma in instrumentalne racionalnosti. Tu seveda namigujem na nekatere predstave konfucijancev in neokonfucijancev o povezavi pristne človečnosti in poduhovljene razumnosti, kot jih najdemo raztresene pri Konfuciju, Menciju, Wang Fuzhiju, Wang Yangmingu, Li Zhiju idr. Podobne zamisli najdemo tudi v delih sodobnejših konfucijancev, in to tako pri tistih, ki so skušali najti povezavo z marksizmom, kot pri onih, ki so tovrstnim poskusom povezovanja odločno nasprotovali.

Zanima mevprašanje, ali nam konfucijanstvolahko ponudi pomembne alternativne koncepte racionalnosti, zlasti takšne, ki ponujajo notranje povezovanje etične zavesti $\mathrm{z}$ racionalnostjo. Takšni koncepti bi morali preseči nasprotja med dualističnimi in instrumentalnimi pojmovanji etike in racionalnosti, ki so tako udomačena $\mathrm{v}$ zahodni filozofiji in družboslovju. Skratka, iščem konceptualni okvir za kultiviranje globoke razumnosti, ki se ne bi zoževala le na kultiviranje vrlin (posebno človečnosti), temveč bi ponudila tudi modro izvajanje vrlin v praksi. Mislim, da so nekateri kitajski misleci $\mathrm{v}$ tem pogledu dosegli višjo raven znanja in modrosti kot zahodni filozofi. Zato so pomemben razlog in predmet nadaljnjega raziskovanja.

\section{Razumnost in racionalnost $v$ zahodni in konfucijanski tradiciji}

Prva stvar, ki jo moramo pri tem po mojem mnenju upoštevati, je dejstvo, da v kitajski filozofiji preprosto ne najdemo pojma ali izraza, ki bi ustrezal pojmoma razuma in racionalnosti, kot ju poznamo v zahodni filozofiji. Kitajski filozofi pa so vendarle uporabljali in razvili nekatere pojme in termine, ki v določeni meri in v določenih kontekstih rabe ustrezajo pojmoma razuma in racionalnosti. Takšni pojmi (termini) so npr. $l i$ (zakon, načelo, struktura), $t i$ in yong (substanca in funkcija, namera in sredstvo), xin (srčna zavest) ipd. Vse nespecifizirane »teorije racionalnosti« v kitajski filozofiji so zato obsojene na to, da so do določene mere arbitrarne. Kitajska filozofska tradicija racionalnost konstruira predvsem kot zmožnost človekove »srčne zavesti« (xin), da se izkaže $\mathrm{v}$ modrih odločitvah, bistrih razpravah in primernem obnašanju, v skladu z najvišjimi vrlinami plemenitih ljudi. To pojmovanje je bolj v skladu s holističnimi nazori o razumnosti kot s pojmovanji o racionalnosti, ki so prevladovala $\mathrm{v}$ zahodni filozofski tradiciji (Bo Mou, 2009, 120-121).

Kitajska (tj. predvsem konfucijanska) pojmovanja racionalnosti zato niso omejena na sposobnost človeka za izdelavo logičnih argumentov in za sodelovanje v smiselni razpravi, temveč zajemajo tudi sposobnost za takšno povezovanje mišljenja in 
čustvovanja, ki ostaja zvesto naravnim in moralnim načelom, ki ohranjajo harmonijo med naravo in družbo.

Zahodna filozofija racionalnost običajno pojmuje kot množico normativnih pravil o oblikovanju prepričanj, sodb, interesov, ciljev ter odločitev posameznikov in skupin, vendar ta pojem zajema tudi pojasnitvene modele človeškega vedenja (npr. v ekonomskem vedenju ljudi) (Elster, 2007, 215-217). Na splošno moramo razlikovati med teoretično in praktično racionalnostjo. Prva se ukvarja $\mathrm{z}$ logično skladnostjo v mišljenju, prepričanjih, pričakovanjih itd., medtem ko se druga ukvarja $\mathrm{z}$ razumnostjo metod in sredstev za doseganje ciljev, načrtov itd. (Spohn, 2002). Ti dve vrsti racionalnosti je kanoniziral že Aristotel v Organonu in Nikomahovi etiki. Svoja izraza najdeta $\mathrm{v}$ ustreznih tipih argumentacije: teoretska racionalnost v logični argumentaciji, druga pa v t. i. praktični argumentaciji. Jürgen Habermas je predlagal še tretjo vrsto racionalnosti, t. i. komunikacijsko racionalnost, ki nam po njegovem mnenju omogoča nenasilno in diskurzivno dosegljivo soglašanje med partnerji $\mathrm{v}$ komunikaciji (Habermas, 1981). V tem smislu ta tretji tip racionalnosti zajema, a obenem tudi presega teoretsko in praktično racionalnost, saj upošteva tudi medsebojno soodvisnost ljudi. Zato bi bilo morda bolje govoriti o »komunikacijski razumnosti« kot o »komunikacijski racionalnosti«, kjer se izraz »razumnost « nanaša na enakopravno obravnavanje drugih oseb, na iskreno zanimanje za dobre medosebne odnose in na skupno prizadevanje komunikacijskih partnerjev za doseganje spoznanja. Ta vrsta razumnosti je že veliko bliže »kitajskemu« razumevanju racionalnosti kot trenutno prevladujočim predstavam o instrumentalni racionalnosti. Lahko bi ji dejali kar »holistična razumnost«.

\section{Pomen analoškega mišljenja za holistično razumnost}

Zanimivo je, da je bila tudi v kitajski kulturi, zlasti v konfucijanstvu, razumnost trdno povezana s posebnimi oblikami argumentacije. Toda medtem ko je bila zahodna filozofska tradicija vseskozi trdno vpeta v vzorce logične argumentacije, ki so jih razvili Aristotel in nato še stoiški logiki, se je kitajska filozofska tradicija prvenstveno nanašala na uporabo analoških sklepov ter na spretno uporabo prispodob in vzorčnih modelov človeškega obnašanja v težavnih situacijah. Tu je šlo za takšne oblike sklepanja, ki jih ne moremo ustrezno izraziti v okviru logične (deduktivne ali induktivne) argumentacije. To dejstvo je imelo velik vpliv na to, kako so na Zahodu razumeli kitajsko filozofijo. Že v klasičnem obdobju kitajske filozofije so predstavniki t. i. moistične šole poskušali sistematizirati in regulirati glavne tokove racionalnega mišljenja, pri čemer so poznali tudi takšne oblike, ki so bile blizu aristotelski silogistični logiki. Na žalost pa to njihovo 
prizadevanje v kasnejši kitajski filozofiji ni pustilo globljih sledi. Tako se je pretrgala nit, ki bi sicer morda lahko povezovala »zahodne« in »kitajske« oblike kultiviranja razumnosti oziroma racionalnosti.

Gledano s stališča zahodne znanstvene in filozofske tradicije, ponuja analoško mišljenje komajda kaj več kot pragmatski nadomestek za eksaktnejše (deduktivne, induktivne ali abduktivne) razlage ali upravičenja (ki temeljijo na znanstvenih zakonih); s stališča kitajske filozofije pa je analoško mišljenje pogosto vrednoteno kot popolno in dokončno. Tako se zdi, kot da stari kitajski misleci niso poznali sistema deduktivnega in induktivnega sklepanja. Vendar podrobnejša analiza starih tekstov pokaže, da so poznali nekatere klasične oblike deduktivnega sklepanja (npr. sklepe tipa modus ponens, modus tollens, silogizme, sorite itd.) (Harbsmeier, 1998), res pa je, da se z njimi niso sistematično ukvarjali. Tako se zdi edini sistem argumentacije, ki bi mu nemara lahko dejali "kitajska logika«, sistem analoškega sklepanja ali, natančneje, širok razred pravil, ki veljajo za analoško sklepanje in so bila v rabi v filozofskih razpravah, čeprav so bila redko neposredno in eksplicitno navajana. Celo če bi bilo mogoče analoške sklepe nadomestiti z ustreznimi eksaktnejšimi oblikami deduktivnega ali vsaj induktivnega sklepanja, so v kitajski tradiciji to pot le redko uporabili.

Kitajski misleci so se praviloma izogibali neposrednim in eksplicitnim verigam sklepanja, občutili so jih za »neduhovne» (Harbsmeier, 1998, 343-353). Že prvi Evropejci, ki so pisali o kitajski miselnosti, so to ravnanje označili kot nesprejemljivo. Leta 1724 je npr. nemški jezuit Biflinger pisal: »Kitajci imajo za zaželeno takšno obliko dokazovanja, ki je za nas vsaj zelo neobičajna: ta sestoji v nepodprtosti njihovih napotkov $\mathrm{z}$ argumenti, pač pa s primeri kakih kraljev in cesarjev« (ibid., 267).

Tradicionalni zahodni pristop $\mathrm{k}$ analoškemu sklepanju je tak, da ga razume kot nepopoln ali defekten deduktivni sklep. Vzemimo npr. logično obliko enostavnega analoškega sklepa:

a ima lastnost $P$;

$b$ je podoben a glede na lastnosti $Q_{1}, Q_{2}, \ldots, Q_{n}$;

torej ima $b$ lastnost $P$ (Juthe, 2005).

Stavek $» b$ je podoben $a$ glede na lastnosti $Q_{1}, Q_{2}, \ldots, Q_{n}$ " lahko pomeni, da ima $b$ iste lastnosti $Q_{1}, Q_{2}, \ldots, Q_{n}$ kot $a$ ali da ima $b$ lastnosti $Q_{1}, Q_{2}, \ldots, Q_{n}$, ki so sistematično podobne lastnostim $Q_{1}, Q_{2}, \ldots, Q_{n}$. Ta sklep bi lahko preoblikovali v primer deduktivnega sklepa, če bi dodali »tiho« premiso, da lastnosti $Q_{1}, Q_{2}, \ldots, Q_{n}$ oziroma $Q_{1}^{r}, Q_{2}, \ldots, Q_{n}^{r}$ implicirajo lastnost $P$, kar je seveda odvisno od primera do primera in tega ni mogoče vnaprej predpostaviti. Zato analoški sklep ni splošno in brezpogojno veljaven. Podobno velja tudi, če bi predpostavili tiho premiso, ki bi 
nam omogočila pretvorbo zgornjega analoškega sklepa v eksplicitni induktivni ali abduktivni sklep (pri tem induktivni in abduktivni sklepi tudi sicer niso splošno veljavni).

Bolj zapleteni primeri analoškega sklepanja vsebujejo več implicitnih hipotez o podobnostih in jih zato ne moremo prevesti v ustrezne verige deduktivnih, induktivnih ali abduktivnih sklepov.

Vzemimo za primer naslednji analoški sklep:

Janez spoštuje svojega očeta;

Janezov odnos do njegovega očeta je podoben odnosu do njegovega učitelja, glede na to, da sta zanj oba osebi z avtoriteto;

torej Janez spoštuje svojega učitelja.

Podobne primere analoških sklepov lahko najdemo v tekstih kitajske filozofije, pogosto so podani v normativni obliki, npr. vsakdo mora spoštovati svojega očeta, odnos do očeta je podoben odnosu do učitelja, ker sta oba osebi z avtoriteto, zato mora vsakdo spoštovati svojega učitelja. Takšni argumenti pa so le redko podani v verbalno eksplicitni obliki, običajno so le implicitno predpostavljeni v tekočih filozofskih ali etičnih razpravah.

Podrobnejša analiza prej navedenega sklepa pokaže, da ga ne moremo preobraziti $\mathrm{v}$ deduktivni sklep, kajti odvisen je od inherentno analoških predpostavk, npr. od predpostavke:

Janezov odnos do svojega učitelja je dovolj podoben njegovemu odnosu do svojega očeta, in sicer $v$ tem, da je avtoriteta njegovega učitelja podobna avtoriteti njegovega očeta.

Ne moremo dati bolj natančnih zadostnih razlogov za to, kdaj gre za zadostno podobnost. Opravka imamo $\mathrm{z}$ inherentno nenatančnimi pojmi oziroma $\mathrm{z}$ nenatančno podanimi odnosi, zato je podani analoški sklep neizogibno neprecizen in nededuktiven. A kljub temu moram poudariti, da je prej naveden sklep lahko za ljudi zelo pomemben, saj nam omogoča prenos ravnanja drugih oseb v določenih okoliščinah na ustrezno lastno ravnanje v primerljivih okoliščinah. Omogoča nam tudi prenos moralne ocene ravnanja drugih oseb na moralne ocene lastnega ravnanja $\mathrm{v}$ primerljivih okoliščinah.

Analoško sklepanje svojo življenjsko moč črpa iz dejstva, da sledi lastnim pravilom sklepanja. Logične oblike analoškega sklepanja pa vendarle presegajo stavčne oblike sklepanja, kajti vsebujejo bolj holistično ali strukturno obliko razmišljanja, kar je tipično za razpravljanje o pojmih, vrednotah in medosebnih odnosih. Domnevam, da lahko nekatere vrste sklepanja in argumentacije $\mathrm{v}$ nezahodnih tradicijah (posebno $\mathrm{v}$ 
kitajski filozofiji in znanosti) mnogo bolje razumemo, če jih razumemo kot sestavne dele holističnega analoškega razmišljanja, kot če jih skušamo tlačiti v sodobne oblike logičnega mišljenja.

Od tod izhaja, da analoškega mišljenja in sklepanja ne moremo zvesti na čisto stavčne, konceptualne in ekstenzionalne oblike sklepanja. Bolj zdravo se mi zdi predpostaviti, da analoško mišljenje in sklepanje uporablja celo vrsto miselnih in semantičnih modelov realnih in imaginarnih situacij, ki vsebujejo strukturno sorodne mreže dejstev, vrednotenj in tipov odnosov. Najpomembnejša poteza teh modelov je, da tiste, ki jih sprejemajo, motivirajo $\mathrm{k}$ temu, da sprejmejo vrsto konceptualnih in praktičnih implikacij ter so se tako pripravljeni angažirati v specifičnih oblikah anticipiranja, presoje, obnašanja in zavzemanja odnosov do drugih ljudi. Seveda te motivacije lahko vsebujejo tudi strinjanje $\mathrm{z}$ določenimi teoretskimi razmisleki, vendar to ni nujno potrebno. Pogosto se namreč zgodi, da so kake bistvene poteze zgolj naznačene ob uporabi ilustrativnih primerjav in niso eksplicitno podane ali opisane. Če podana interpretacija drži, moramo analoško mišljenje pojmovati kot samostojni način mišljenja in sklepanja ter le kot nepopolno ali nezadostno obliko logičnega sklepanja. Pravi smisel analoškega mišljenja vidim v holističnih in strukturnih oblikah mentalnih ali semantičnih modelov, ki so lahko povezani s specifičnimi situacijami ali s svetom kot celoto. Ta oblika mišljenja in sklepanja predstavlja posebno, sebi lastno obliko neinstrumentalne racionalnosti, ki človekovo »srce in um « postavlja v usklajen medsebojni odnos, in to obenem s sprotnimi spremembami v naravi in človeškem svetu.

Klasične in paradigmatske primere tovrstne racionalnosti lahko najdemo pri zgodnjih konfucijancih, predvsem pri Menciju. Sicer že znani Konfucijev izrek »Kar ne želim, da bi ljudje prizadeli meni, tega tudi sam nočem storiti njim « (Konfucij, 2005, V/12: 27), predpostavlja komparativni model, ki nam omogoča, da izpeljemo obojestranski miselni in domišljijski prenos od nas samih k drugim in od drugih $\mathrm{k}$ nam samim. Enak rezultat lahko dosežemo tudi z disciplinirano prakso nanašanja svojih občutij in svojega vedenja do občutenja in vedenja drugih ljudi. Mencij je to metodo razširil tako, da je vključil prirojene, čeprav speče človeške vrline in vrednote (človečnost, pravičnost, dostojanstvo in modrost), ki jih moramo znati spretno razširiti od najenostavnejših vzorčnih primerov $\mathrm{k}$ podobnim primerom, vzetim iz našega vsakdanjega življenja. Mencij je te prirojene potencialne vrline primerjal z nežnimi poganjki, ki jih moramo nežno negovati z nenehnim kultiviranjem vrlin. Mencij piše:

Vsi ljudje imajo te štiri zasnove v sebi, če bi jih vse znali razširiti in izpopolniti, bi bilo to kakor ogenj, ki se je vnel, kot izvir, ki je privrel na dan. Kdor te zasnove izpopolnjuje, je sposoben varovati svet, kdor pa jih ne izpopolnjuje, ne more služiti niti svojim staršem (Mencij, 2005, III/6: 176). 
Po Bryanu v Nordenu moramo pri Menciju razlikovati med dvema tipoma ekstenzije: kognitivno in čustveno: »Kognitivna ekstenzija je v uvidenju pomenljivih podobnosti med situacijami, v katerih se je kdo primerno etično odzval. Čustvena ekstenzija pa je v tem, da imamo ustrezne etične želje, stališča in čustva ter delujemo njim ustrezno« (Norden, 2004, 150).

Oba tipa ekstenzije uporabljata analoško metodo, kjer sklepi temeljijo na podobnostih med vzorčnimi primeri etičnega vedenja in našo sedanjo situacijo. Mencijev pristop pa vendarle ni le kognitivna metoda, pač pa vsebuje mešanico empatije, presoje in vedenja, ki ga pridobimo v procesu oblikovanja svojega moralnega značaja. Van Norden dokazuje, da je Mencijevo pojmovanje praktične modrosti bolj podobno umetelnosti obrtnika kot pa logika. Obrtnik mora osvojiti tehnike in modrost, ki so jih zbrali njegovi predniki, kar je sposobnost, ki je odvisna od konteksta. Vendar zato še zdaleč ni iracionalna:

Razmišljanje $\mathrm{v}$ okviru praktične modrosti kot zelo kontekstualno odvisne spretnosti Mencija ni vodilo v etični antiracionalizem. Racionalnost terja, da pomenljivo podobne primere podobno obravnavamo. To ni zahteva racionalnosti, po kateri naj se pomenljive podobnosti obravnavajo po zelo splošnih pravilih, ali da naj se dober praktični mislec sklicuje na splošna pravila v svojih zaključkih (prav tam, 173).

Čeprav nam praksa ekstenzije, kot jo je razumel Mencij, svetuje, da se ravnamo po vzorčnih primerih etično pravilnega ravnanja, to ne pomeni slepega posnemanja, temveč prej posnemanje, ki ostri našo zmožnost za konkretne moralne presoje in odločitve. Mencij nam tako svetuje, da smo včasih obvezani delovati tako, da kršimo določena formalna pravila delovanja, če čutimo, da nasprotujejo našim moralnim obvezam do nas samih (npr. ohranjanje svojega moralnega obraza) ali do drugih ljudi (npr. ljubezni do drugega).

Ta prefinjena verzija razumnosti kombinira gojenje človečnosti, dobrohotnosti (ren) in racionalnosti, razvil pa jo je Mencij in nekateri drugi humanistično usmerjeni konfucijanski misleci. Ta oblika razumnosti je izjemno pomembna za sodobni svet, vendar menim, da kitajsko tradicijo obremenjuje velika ovira, namreč določeno neravnotežje med gojenjem vrline (de) in spoštovanjem človeka kot posameznika $(g u i)$.

\section{Preseganje razcepa med kultiviranjem vrlin in spoštovanjem dostojanstva vsakega posameznika}

Številni filozofski teksti iz kitajske tradicije so polni različnih razprav o človečnosti in dobrohotnosti (ren) ter o gojenju človečne srčne zavesti (ren-xin) in vrline (de). $\mathrm{V}$ 
teh razpravah sta bila vrednost in dostojanstvo posameznika tipično umerjena glede na to, kakšne moralne vrline je ta posameznik razvil. Sicer je veljalo, da moramo enako spoštovati vse ljudi, vendar le zato, ker imajo vsi ljudje prirojeni potencial za razvoj človečnega duha in vrlin. Razlike med ljudmi naj bi bile rezultat različnih okolij in različne vzgoje. Po tem pojmovanju posamezen človek nima dostojanstva sam po sebi, temveč ga pridobi šele skozi svoj moralni razvoj. Ta nazor so najbolj vneto podpirali konfucijanci, a najdemo ga lahko tudi pri daoistih in kitajskih budistih. Temu ustrezno tudi ni bilo pojma načelnega spoštovanja vsakega človeka kot takšnega.

Odsotnost pojma načelnega spoštovanja vsakega posameznika je bila verjetno povezana s pomembno vlogo ritualnosti v konfucijanski filozofiji, čeprav to najbrž ni bil edini razlog. Domnevam, da je organicistično pojmovanje človeške družbe, ki je bilo zelo razširjeno v vsej kitajski kulturi, imelo globlji vpliv na verovanje, da moramo vsakega posameznika ceniti glede na njegovo "mesto « v družbi, obnašanje, odnose $z$ okolico itd. Tako je cela vrsta ljudi, zlasti iz nižjih družbenih slojev, preprosto izpadla iz obsega tistih ljudi, ki si zaslužijo spoštovanje kot ljudje. Edino izjemo od te težnje najdemo pri nekaterih daoističnih in budističnih mislecih, ki so govorili o enaki naravi vseh ljudi, ne glede na družbeni izvor, položaj, dosežene vrline itd. Vendar je šlo pri tem v glavnem za nekatere mistike in modrece, ki so se zavestno distancirali od družbe, se skušali poenotiti z naravo in tako uresničiti pravo človekovo naravo.

$\mathrm{V}$ zahodni kulturi je po drugi strani močno razširjeno zagovarjanje predstave o svobodnem posamezniku in brezpogojni vrednosti vsakega človeka, tj. o prirojenem dostojanstvu vsakega posameznika, ki ne more biti porušeno ali zmanjšano s silo, rasizmom, razrednimi predsodki itd. Ljudje, naj bodo moralno vrli ali ne, so po tem pojmovanju ne glede na zunanje okoliščine nosilci temeljnega dostojanstva osebe.

Ta predstava se je v evropski kulturi močno zakoreninila in se dodatno utrdila $\mathrm{z}$ nastankom moderne evropske kulture. V moderni Evropi se je spoštovanje vsakega posameznika in njegovega dostojanstva povezovalo $\mathrm{z}$ ustreznim obsegom človekovih pravic in državljanskih svoboščin. Tovrstno spoštovanje ter spremljajoč obseg pravic in svoboščin je naraščalo vzporedno s krepitvijo modernizacije ter razvojem individualizma in demokracije. Ta razvoj je kot kontrast spremljalo zmanjševanje vpliva dominantnih religij in univerzalnih moraličnih sistemov ter posledično zmanjševanje pomena moralnih vrlin. Zaradi tega je pojem vrline postopno izginjal iz horizonta evropske kulture, prekrila pa ga je mreža pojmov, kot so individualnost, človekove pravice in državljanske svoboščine.

Če nekoliko poenostavim, je razvoj dveh različnih kultur - evropske (zahodne) in kitajske - ustvaril razcep med dvema etičnima perspektivama, ki sta vsaka zase potencialno nevarni: razcep med dostojanstvom posameznika brez vrlosti vsakega 
posameznika na eni strani in med osebno vrlostjo brez dostojanstva vsakega posameznika na drugi strani. Če skušamo ta razcep kantovsko označiti, bi lahko dejali, da je dostojanstvo brez vrlosti prazno in vrlost brez dostojanstva slepa. Gre torej za dve skrajnosti, pri čemer prva vodi do moralne izsušenosti posameznika in se zaustavlja pred naporom za razvoj moralnega značaja posameznika, druga pa vodi k moralnemu in socialnemu elitizmu, ki ostro razmejuje med elito »vrlih« in »modrih« ter množico posameznikov »brez obraza«, ki jim kapriciozno vladajo in jih po svoje »oblikujejo« različni vladarji.

Kar je torej res potrebno, so skupni napori za hkratno doseganje človečnosti in dostojanstva posameznika. Lahko bi dejali, da na Zahodu primanjkuje praktičnih sredstev za sistematično kultiviranje vrlin, ki gradijo človečnost, medtem ko Kitajski primanjkuje spoštovanje dostojanstva posameznika ter $s$ tem povezanih človekovih pravic in državljanskih svoboščin. Jasno pa je, da moralične sinteze, ki bi združevala oba vidika, ne moremo doseči $\mathrm{z}$ enostavnim mešanjem različnih idej in kulturnih tradicij, temveč potrebujemo nekaj, kar zadira $\mathrm{v}$ samo esenco globalnih etičnih usmeritev in ustvarja njim ustrezne družbene razmere.

\section{Zaključek: razumnost in osebno zadovoljstvo kot vodili človečnosti}

Mencijeva filozofija nam je lahko v tem prizadevanju v veliko pomoč. Zdi se, da Mencij nikoli ni sprejemal dualizma med vrlimi (plemenitimi) in nevrlimi (običajnimi) ljudmi, po katerem naj bi le prvi zaslužili, da jih imenujemo človeška bitja. S tega vidika ga lahko imamo za enega od izvornih promotorjev izvorne človečnosti. Čeprav lahko najdemo podobne mislece tudi na Zahodu (tako med zagovorniki religioznega kot nereligioznega humanizma), so bile njihove "metode« za kultiviranje izvorne človečnosti povečini nerazvite ali nezadostno razvite. Če želimo kultivirati osnovne moralne vrline, sta ključnega pomena dobra vzgoja in naklonjeno družbeno okolje.

To ne pomeni, da branim moralni rigorizem v Kantovem smislu, ki ognjevito nasprotuje vsakemu mešanju moralnega delovanja s "podmoralnimi« (npr. čustvenimi) goni. Kant bi morda Mencijev primer spontanega altruizma (npr. pri reševanju otroka pred neposredno nevarnostjo) kritiziral kot moralično nečistega, ker se oseba, ki je rešila otroka, ob tem zaradi svojega dejanja počuti srečno in je torej k temu dejanju ni gnal zgolj čut moralne dolžnosti. Vendar se moram v tem primeru postaviti na stran Mencija in ne Kanta. Če kdo občuti izvorno radost, kadar pomaga ljudem v stiski, moramo njegovo skrb za moralne dolžnosti in njegovo radost ob tem razumeti kot dva vidika iste (altruistične) usmeritve, ki stremi k pomoči drugim in ob tem doživlja radost. Moralne norme in obveznosti poudarjajo soodvisnost med ljudmi in naše drže 
do drugih, medtem ko radost, ki spremlja moralno delovanje, poudarja naš odnos do dobrobiti drugih ljudi in naše zavzemanje za notranjo rast tako nas samih kot drugih, s katerimi smo v odnosih.

Če ločeno analiziramo ta dva vidika izvorne altruistične usmeritve, se nam morda zazdita medsebojno izključujoča. To lahko vodi do trka med etiko dolžnosti in iskanjem osebne sreče. Tak pogled pa je napačen, ker z njim ne moremo dojeti izvorne moralične usmeritve, ki temelji na občutjih, željah, racionalnosti in sprejemanju moralnih dolžnosti. Nasprotni pogled (ki ga branijo zlasti angleški empiristi in sodobni ekonomski teoretiki) je vendarle prav tako napačen, ker altruistično ravnanje, povezano z zadovoljitvijo, ki je potencialno vsebovana v njem, pojmuje zgolj kot izraz interesov jaza, če ne kar razsvetljenega egoizma posameznika. Oba pogleda stremita k spregledu tega, kar je bilo tako jasno Menciju in drugim mislecem, namreč da smo ljudje opremljeni z moralnimi potenciali, ki jih lahko kultiviramo in k njim stremimo, tako da postanemo sposobni za razumno ravnanje, v skladu s svojim moraličnim razumevanjem aktualnih medosebnih situacij. To je ravno tista vrsta ravnanja, ki nas usposablja za uravnoteženje razuma in srca, tj. za razumnost, razumljeno kot obliko neinstrumentalne racionalnosti.

Če kdo stori kako altruistično dejanje v situaciji, kjer pričakujemo, da bi vsak »normalen « človek enako ali podobno deloval, je pametno sklepati, da njegova želja po pomoči, njegovo zadovoljstvo zaradi te pomoči drugim itd. nikakor ne nasprotujejo njegovi moralni presoji, temveč dejansko poudarjajo moralno kvaliteto njegovega početja. Zdi se, da ni nobenega notranjega konflikta med našimi samointeresi in našo moralnostjo; nasprotno, dejanska moralnost in dejanska razumnost se pojavita na ozadju dinamične medigre med našim stremljenjem po samorealizaciji in našim moralnim stremljenjem.

Moralni dogmatiki vseh religioznih in nereligioznih verovanj (zdi se, da so slednji najbolj prevladovali prav v kitajski kulturi) so ustvarili dozdevno nepremostljiv razcep med »občutenjsko vsebino« ter »spoštovanjem moralnih in/ali religioznih pravil«. Ena od resnejših posledic takšnega pristopa je, da ljudje občutijo nenehno nezadovoljstvo s svojim življenjem in izgubljajo temeljno zaupanje sami vase. Ta posledica obratno spodbuja skeptični odmik do prostovoljnega »dajanja« samega sebe drugim ali do spontanega »sprejemanja « drugih, kakršni pač so. Moralni dogmatizem nam namesto tega ponuja "prodajanje« sebe drugim in »kupovanje« drugih. Zdi se, da globalizacija pospešuje te popačene poti dajanja in jemanja, vendar ta proces obenem prihaja do svojega konca, kajti konec koncev je odvisen prav od izvornih načinov dajanja in jemanja, ki še niso podlegli ekonomsko določenim pojmovanjem medosebnih odnosov. 
V knjigi An evidential Study of the Meaning of the Terms in the Book of Mencius (Dokazna študija pomena terminov v Mencijevi knjigi) je neokonfucijanski učenjak Dai Zen podal kar ustrezen opis tega temeljnega povezovanja med razumnostjo, moralno intuicijo in zadovoljstvom:

Razumevanje načela $(l i)$ in spoštovanje radostita um, zvoki radostijo uho in barve radostijo oči, to je pač človeška narava. Okusi, zvoki, barve so povezani s stvarmi, vendar stopajo v stik z mojo krvjo in čijem. Načelo in spoštovanje imata opravka $z$ dogajanjem okrog nas in stopata v stik z mojim umom in mojo spoznavno zmožnostjo. Kri, či, um in spoznavna zmožnost imajo vsak svoje potenciale. Usta lahko razlikujejo med načelom in spoštovanjem. ... Načelo in spoštovanje smo analizirali izhajajoč iz pogojev, ki vladajo dogajanjem in situacijam ter prihajajo v stik z mojim umom in mojo spoznavno zmožnostjo. Zato lahko razlikujem med njimi in v njih uživam. To, kar me v njih najbolj radosti, je tudi najvrednejše (nav. v Zhang Dainan, 2002, 407).

$\mathrm{V}$ tem citatu je $\mathrm{v}$ grobem orisana praksa povezovanja etičnih razmislekov, zaznavanja in občutja. Škoda je, da je ta praksa ostala v glavnem neizgovorjena osnova človečnosti in razumnosti v starejših in novejših oblikah konfucijanstva. Verjamem, da sodobni človek potrebuje prav takšno prakso, če naj pridobimo širše in globlje pojmovanje človečnosti in razumnosti.

\section{Literatura}

Elster, J., Explaining Social Behavior, Cambridge 2007.

Habermas, J., Theorie des kommunikativen Handelns. Bd. 1., Frankfurt na Majni, 1981.

Harbsmeier, C., Language and Logic, v: J. Needham (ur.), Science and Civilisation in China. 7/I. Cambridge 1998.

Ivanhoe, P. J., Van Norden, B. W., Readings in Classical Chinese Philosophy, Indianapolis 2005.

Juthe, A., Argument by analogy, Argumentation, 19, 2005, str. 1-27.

Konfucij, Lun yu (Pogovori), v: Konfucij, Mencij, Nauk o sredini, Veliki nauk (pr. M. Milčinski), Ljubljana 2005.

Mencij, Nauk o sredini, Veliki nauk, v: Konfucij, Mencij, Nauk o sredini, Veliki nauk (pr. M. Milčinski), Ljubljana 2005.

Mou, B., Chinese Philosophy A-Z, Edinburgh 2009.

Spohn, W., The many facets of the theory of rationality, Croatian Journal of Philosophy, 6, 2002, str. 249-264. 
Van Norden, B., The virtue of righteousness in Mencius, v: Confucian Ethics. A Comparative Study of Self, Autonomy, and Community (ur. Shun, K.-L., Wong, D. B.), Cambridge 2004, str. 148-182.

Zhang, D., Key Concepts in Chinese Philosophy, Peking 2002. 


\section{Andrej Ule \\ Pomen konfucijanske misli za ohranjanje človečnosti in razumnosti $v$ sodobnem svetu}

Ključne besede: humanost, racionalnost, razumnost, konfucijanstvo, sklepanje po analogiji, samouresničenje

Govorim o možnosti sinteze človečnosti in racionalnosti v sodobnem svetu ter se sprašujem, ali in kako nam pri tem prizadevanju lahko pomaga kitajska filozofska misel, zlasti konfucijanska tradicija. V kitajski filozofski tradiciji je racionalnost grobo vzeto razumljena kot sposobnost človeške »srčne zavesti« (xin) za modro razmišljanje, pametno razpravljanje in ravnanje, ki je v skladu $\mathrm{z}$ najvišjimi vrlinami plemenitega človeka. To jebolj podobno konceptu celostne razumnosti kot pa racionalnostiv zahodni filozofski tradiciji. Razumnost v kontekstu kitajske kulture, zlasti konfucijanstva, je močno vezana na specifične oblike argumentacije, predvsem na sklepanje po analogiji ter uporabo metafor in vzorčnih modelov vedenja, ki jih ni mogoče stlačiti v okvire logične (deduktivne ali induktivne) argumentacije. Ob naslonitvi na Mencijevo metodo »ekstenzije« vrojenih, potencialnih človeških vrlin (človečnosti, pravičnosti, dostojnosti in modrosti) od njihovih paradigmatskih primerov na podobne primere v vsakdanjem življenju lahko bolje razumemo gojenje in izvajanje razumnosti kot sinteze racionalnosti in človečnosti. Pri tem ne vidim nobenega notranjega nasprotja med samointeresi posameznika in njegovo moralnostjo. Dejansko moralnost in dejansko razumnost vidim prav v notranji povezanosti stremljenj posameznika po samouresničenju in moralične usmeritve posameznika. 


\author{
Andrej Ule
}

\title{
The Role of Confucian Thought in Preservation of Humanity and Reasonableness in the Modern World
}

Keywords: humanness, rationality, reasonableness, Confucianism, analogical inference, self-realization

The article examines the possibility of providing a synthesis of humanness and rationality in the modern world, and considers whether, and how, Chinese philosophical thought in general and Confucian tradition in particular might help us in this endeavour. Chinese philosophical tradition broadly construes rationality as the ability of the human "heart mind" (xin) to engage in wise deliberation, clever discussion, and proper conduct carried out in accordance with the highest virtues of the gentleman. This conception is much more in tune with holistic views of reasonableness than with ideas about rationality that have become rooted in the Western philosophical tradition. In the context of Chinese culture, especially Confucianism, reasonableness is firmly associated with distinct forms of argumentation, primarily with those of analogical inference, metaphor use, and paradigmatic behavioural models which cannot be expressed within the framework of logical (deductive or inductive) reasoning. By focusing on Mencius's method of "extending" innate human virtues (humanness, righteousness, dignity, and wisdom) from their paradigmatic cases to parallel cases from everyday life, it is possible to get a better insight into the idea of cultivating and practicing reasonableness conceived as a synthesis of humanness and rationality. There seems to be no internal conflict between our self-interests and our morality; on the contrary, actual morality and actual reasonableness emerge against the backdrop of the dynamic interplay between our striving for self-realization and our moral orientation. 